\title{
Serabi Milenial (Serial) Sebagai Inovasi Kue Serabi Unggulan di Desa Borok Toyang Guna Meningkatkan Eksistensi Produk Lokal: Pengabdian Masyarakat
}

\author{
Rabiatun Adawiah $^{1 *}$, Siti Raihanun ${ }^{2}$, Rohana Sopiati ${ }^{3}$, Lalu Kusnendar Atmanegara ${ }^{4}$, Ria Duana Saptia ${ }^{5}$, \\ Saprizal Hadisaputra ${ }^{6}$, Eka Junaidi ${ }^{6}$, Jannatin 'Ardhuha ${ }^{7}$, Mochammad Asyhar ${ }^{8}$, Syahrial Ayub ${ }^{9}$ \\ 1,3,6 Program Studi Pendidikan Kimia, FKIP, Universitas Mataram, Mataram, Indonesia \\ ${ }^{2}$ Program Studi Pendidikan Sosiologi, FKIP, Universitas Mataram, Mataram, Indonesia \\ ${ }^{4,8}$ Program Studi Pendidikan Bahasa dan Sastra Indonesia, FKIP, Universitas Mataram, Mataram, Indonesia \\ ${ }^{5}$ Program Studi Pendidikan Pancasila dan Kewarganegaraan, FKIP, Universitas Mataram, Mataram, Indonesia \\ 7,9 Program Studi Pendidikan Fisika, FKIP, Universitas Mataram, Mataram, Indonesia
}

DOI: https://doi.org/10.29303/jpmsi.v3i1.92

Citation: Adawiah, R., Raihanun, S., Sopiati, R., Atmanegara, L. K., Saptia, R. D., Hadisaputra, S., Junaidi, E., 'Ardhuha, J., Ashyar, M., Ayub, S. 2021. Serabi Mileniar (Serial) sebagai Inovasi Kue Serabi Unggulan di Desa Borok Toyang Guna Meningkatkan Eksistensi Produk Lokal: Pengabdian Masyarakat. Jurnal Pengabdian Masyarakat Sains Indonesia (JPMSI). 3(1):235-239.

Article history

Received: January $12^{\text {th }} 2021$

Revised: June $20^{\mathrm{th}} 2021$

Accepted: June $30^{\text {th }} 2021$

*Corresponding Author:

Rabiatun Adawiah, Universitas

Mataram, Mataram, Indonesia;

Email:

rabiadawiah2712@gmail.com

\begin{abstract}
Abstrak: Program kegiatan 1000 Wirausaha Baru merupakan salah satu program kegiatan pada KKN New Normal Universitas Mataram yang dilaknasakan selama empat puluh lima hari di Desa Borok Toyang, Sakra Barat. Program ini bertujuan untuk melatih masyarakat di desa tersebut agar dapat mengembangkan kreativitas dan meningkatkan inovasi dalam berwirausaha. Serabi milenial (serial) merupakan salah satu produk lokal di Desa Borok Toyang yang saat ini masih dalam bentuk kue sederhana. Alasan pemilihan produk serial ialah untuk meningkatkan eksistensi produk lokal di semua kalangan termasuk di kalangan generasi milenial. Bentuk pengabdian yang dilakukan yaitu dengan melakukan sosialisasi pada ibuibu yang terdaftar dalam Pogram Keluarga Harapan (PKH). Terpilih sebanyak lima orang untuk mengikuti kegiatan sosialisasi di Dusun Dasan Lekong. Metode pembuatan serial masih secara tradisional dengan menggunakan cetakan sederhana. Perbedaan kue serial dengan serabi biasa ada pada tambahan varian warna dan varian toping. Analisis ekonomi usaha serial antara lain: BEP (Break Event Point) dalam unit yaitu 372 biji kue serabi, B/C Ratio yaitu 6,6 dan ROI (Return On Investment) sebanyak 33\%. Hasil tersebut menggambarkan bahwa serabi milenial layak dikembangkan sebagai usaha dengan keuntugan besar. Tindak lanjut untuk usaha serial antara lain pembuatan surat izin usaha dagang, pembuatan surat izin BPOM dan pembuatan toko serial.
\end{abstract}

Kata kunci: P1000WB, Usaha, Serial

\section{Pendahuluan}

Perkembangan kuliner di Indonesia mengalami kenaikan pada akhir-akhir ini. Industri kuliner akan tetap menjadi andalan pada beberapa produksi non migas. Perkembangan industri kuliner menjadi andalan karena banyaknya permintaan dari dalam negeri terutama pada masa Covid-19. Hal ini disebabkan oleh program pemerintah yang memberlakukan PSBB di seluruh Indonesia. Selain itu, Khoirunnisa (2013) menambahkan bahwa Indonesia saat ini berpartisipasi aktif di dalam forum Codex Allimentarius Comunission (CAC) yang bertujuan untuk membahas satandar mutu dan keamanan pangan dunia yang terkait dengan kepentingan industri. Proses integrasi dari perdagangan bebas Masyarakat Ekonomi ASEAN (MEA) tahun 2015, sektor pangan merupakan salah 
Adawiah et al, Jurnal Pengabdian Masyarakat Sains Indonesia 2021, 3 (1): 235-239. DOI: https://doi.org/10.29303/jpmsi.v3i1.92

satu sektor yang semakin dipercepat pelaksanaannya. Pembahasan dilakukan melalui Prepared Foodstuff Product Working Group melalui Forum ASEAN Consultive Committee dan perintisan saling pengakuan untuk sektor pangan olahan. World Street Food Congress di Singapura menempatkan empat makanan khas nusantara dalam daftar 20 kuliner kaki lima terbaik di dunia.

Indonesia merupakan negara yang mempunyai banyak kuliner khas dari masingmasing daerah. Salah satu daerah yang sedang mengembangkan industri kuliner ialah Nusa Tenggara Barat (NTB). NTB saat ini sedang mengembangkan kuliner lokal sebagai penunjang Halal Tourism. Menurut Suteja \& Wahyuningsih (2019) Pulau Lombok merupakan salah satu wilayah NTB yang paling terkenal dengan kuliner lokalnya. Keberagaman kuliner lokal menjadi potensi wisata yang kerap menarik wisatawan asing.

Kue serabi merupakan kuliner lokal di Pulau Lombok yang terkenal di kalangan masyarakat. Hal ini terlihat di beberapa titik kecamatan bahkan desa masih mengonsumsi kue serabi sebagai kuliner umum. Misalnya di Desa Borok Toyang, Kecamatan Sakra Barat, masih banyak menjadikan kue serabi sebagai hidangan pembuka untuk melakukan kegiatan sehari-hari. Kue serabi yang diproduksi masyarakat masih biasa dan belum ada inovasi. Sebagai solusi dari permasalahan tersebut, kami mengangkat judul KKN "Serabi Milenial (Serial) Sebagai Inovasi Kue Serabi Unggulan di Desa Borok Toyang Guna Meningkatkan Eksistensi Produk Lokal." Produk kue serabi ini dibuat dengan pemanfaatan trend kuliner saat ini seperti penambahan variasi rasa dan variasi estetis. Kue serabi akan dibuat lebih kekinian agar banyak diminati oleh masyarakat terutama kaum milenial yang saat ini lebih cenderung mengonsumsi makanan cepat saji berpotensi kurang baik bagi kesehatan.

PKH adalah program pemerintah yang memberikan bantuan sosial kepada rumah tangga yang masih memiliki perilaku miskin berdasarkan pada kriteria tertentu. Tujuan dari PKH yaitu untuk mengurangi beban RTSM, memutus rantai kemiskinan dengan menyoroti dua bidang seperti kesehatan dan pendidikan (Takaredase $d k k, 2019$ ). Ibu-ibu PKH menjadi sasaran pengabdian untuk program KKN P1000WB Universitas Mataram di Desa Borok Toyang. Desa Borok Toyang memiliki 7 Dusun yang salah satunya adalah Dusun Dasan
e-ISSN : 2715-2537

p-ISSN : 2715-2545

Lekong. Ibu-ibu yang terdaftar sebagai penerima PKH di Dusun Dasan Lekong kurang lebih 25 orang. Bentuk pengabdian yang dilakukan antara lain melatih ibu-ibu PKH untuk membuat serial dan memasarkannya secara online.

\section{Metode}

Pelaksanaan KKN New Normal dilaksanakan dengan memperhatikan protokol kesehatan untuk mengurangi penyebaran Covid-19. Waktu pelaksanaannya dimulai dari tanggal 23 November 2020 - 7 Januari 2021. Tempat pelaksanaannya di Desa Borok Toyang, Kecamatan Sakra Barat, Lombok Timur. Tahapan pelaksanaan antara lain tahap persiapan, tahap produksi, tahap promosi, tahap pemasaran, tahap evaluasi dan tahap pembuatan video dan leaflet.

1. Tahap Persiapan

Pada tahap persiapan ini dilakukan selama tiga hari yaitu pada hari Jum'at - Minggu tanggal 2729 November 2020. Tahap persiapan terdiri dari pembuatan proposal KKN, melakukan survei bahan serta perlengkapan yang akan digunakan untuk produksi serial dan melakukan percobaan pembuatan produk serial (Serabi Milenial). Pada tahap persiapan juga dilakukan sosialisasi program kepada Kepala Desa Borok Toyang. Sosialisasi ini tidak melibatkan ibu-ibu PKH dikarenakan masih adanya Covid-19. Sosialisasi dilakukan dengan mengunjungi rumah ibu-ibu PKH yang diambil sebagai sampel pengabdian.

2. Tahap Produksi

Produksi dilakukan selama 16 kali selama kegiatan KKN berlangsung yakni empat kali dalam satu minggu. Tahap produksi berlangsung di salah satu rumah masyarakat yang terdaftar sebagai penerima PKH. Alat produksi: cetakan, penggiling tepung, parutan kelapa, panci, sendok, bakul dan nampan. Bahan produksi: beras, kelapa, keju, messes, coklat, kacang, daun pandan, buah-buahan lokal (pisang, mangga dan anggur merah), susu dan margarin. Langkahlangkah produksi:

a. Beras direndam selama kurang lebih 30 menit.

b. Beras yang telah direndam kemudian ditiris dan digiling.

c. Buah kelapa diparut dan diperas. Lalu hasil perasan disaring dan dimasak. 
Adawiah et al, Jurnal Pengabdian Masyarakat Sains Indonesia 2021, 3 (1): 235-239. DOI: https://doi.org/10.29303/jpmsi.v3i1.92

d. Hasil perasan kelapa yang telah mendidih kemudian dituang pada tepung untuk membuat adonan.

e. Adonan diaduk sampai tercampur rata supaya tidak ada tepung yang menggumpal.

f. Adonan dipisahkan pada wadah menjadi dua bagian. Kemudian masing-masing wadah diberikan varian warna dari daun pandan dan coklat.

g. Cetakan diolesi dengan margarin.

h. Adonan dituang dalam cetakan lalu didiamkan sampai tekstur adonan memadat.

i. Kue serabi diangkat dari cetakan dan didinginkan minimal 30 detik.

j. Kue serabi ditambahkan toping seperti keju, susu, messes, buah-buahan lokal dan kacang.

k. Kue serabi dikemas menggunakan kotak dan ditempelkan sticker serial pada permukaan kotak.

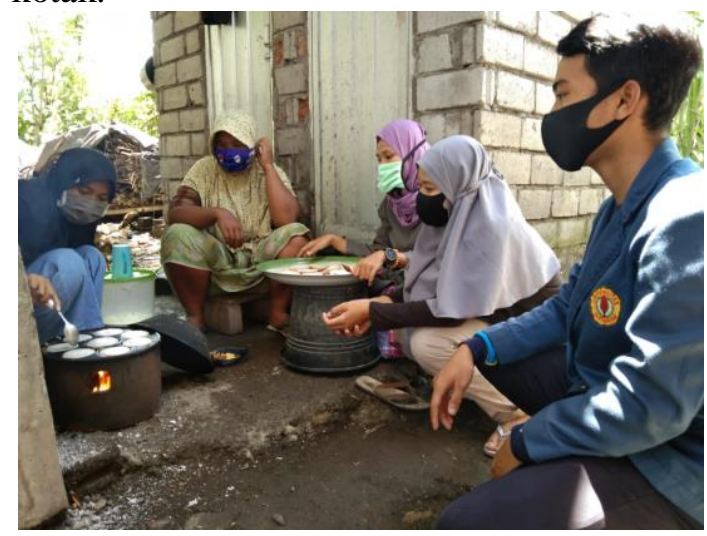

Gambar 1. Pelatihan Ibu-ibu PKH

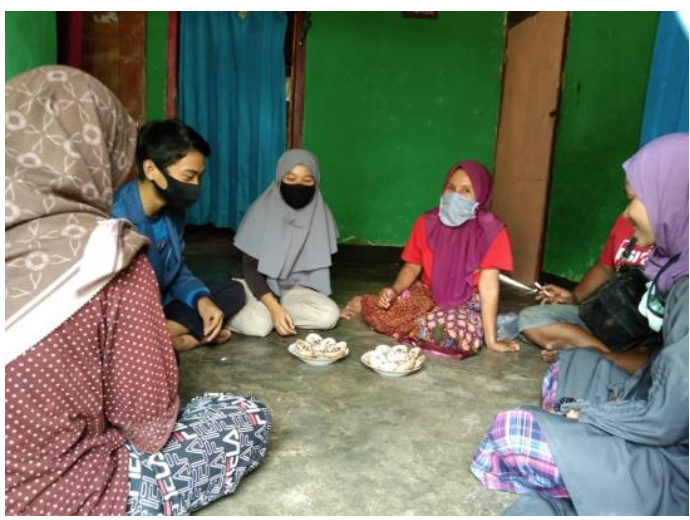

Gambar 2. Pelatihan Ibu-ibu PKH

\section{Tahap Promosi}

Tahap promosi dilakukan dengan memanfaatkan media sosial seperti facebook, WA dan berjualan langsung di sekitar rumah tempat produksi yaitu di Desa Borok Toyang. Tahap promosi dilakukan selama produksi serial yaitu
e-ISSN : 2715-2537

p-ISSN : 2715-2545

sebanyak 16 kali (empat kali dalam seminggu). Ibu-ibu PKH juga diajarkan cara memasarkan melalui sosial media.

4. Tahap Evaluasi

Tahap evaluasi dilakukan selama enam hari dengan penyusunan laporan akhir program dan penyusunan artikel ilmiah. Evaluasi ini bertujuan untuk melihat keberhasilan program, mengoreksi kekurangan dari program termasuk mengevaluasi pengeluaran dan pendapatan.

5. Tahap Pembuatan Video dan Leaflet

Pembuatan leaflet dilakukan pada hari Jum'at, 1 Januari 2021. Sedangkan pengambilan video dilakukkan pada hari Sabtu, 2 Januari 2021. Video berisi tentang berbagai program yang telah dilakukan termasuk serial dan program tambahan lainnya. Serta leaflet berisi tentang tahapan produksi dan keunggulan produk serial.

\section{Hasil dan Pembahasan}

Nama produk serabi yang dibuat ialah Serial (Serabi Milenial). Alasan pemilihan nama ini karena sesuai dengan selera makanan generasi milenial. Generasi milenial sekarang kurang menyukai kuliner lokal seperti halnya kue serabi biasa. Oleh karena itu, inovasi ini bisa menambah minat generasi milenial untuk mencintai produk lokal. Pada bagian logo dicantumkan nama produk serial dan gambar produk. Sedangkan piring pada logo produk menggambarkan tentang kemasan yang identik waste zero.

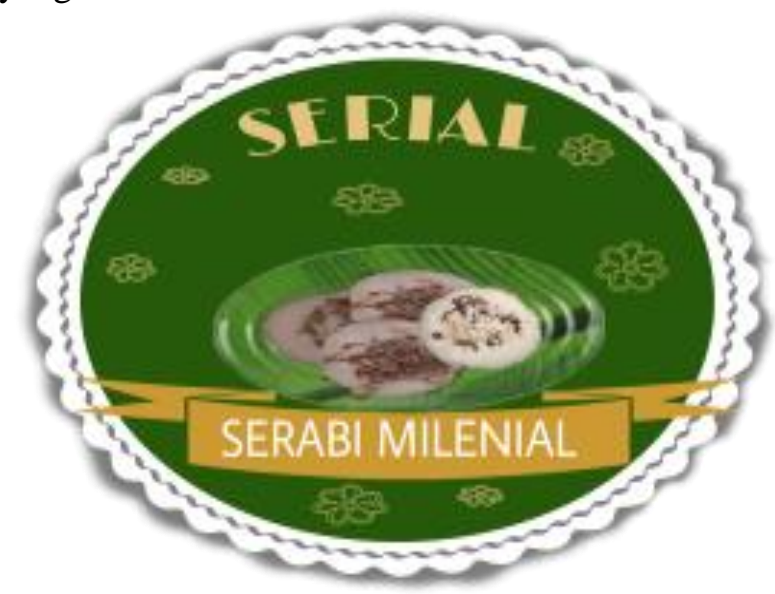

Gambar 3. Logo Produk

Adapun beberapa keunggulan produk serial antara lain:

1. Mengembangkan kuliner lokal seperti kue serabi yang sudah jarang diproduksi oleh masyarakat. 
Adawiah et al, Jurnal Pengabdian Masyarakat Sains Indonesia 2021, 3 (1): 235-239. DOI: https://doi.org/10.29303/jpmsi.v3i1.92

2. Kemasan yang memanfaatkan kotak kue untuk mengurangi limbah plastik.

3. Produk yang menerapkan daily health dengan pemanfaatan buah-buahaan lokal.

4. Kuliner tradisional yang diubah menjadi produk modern.

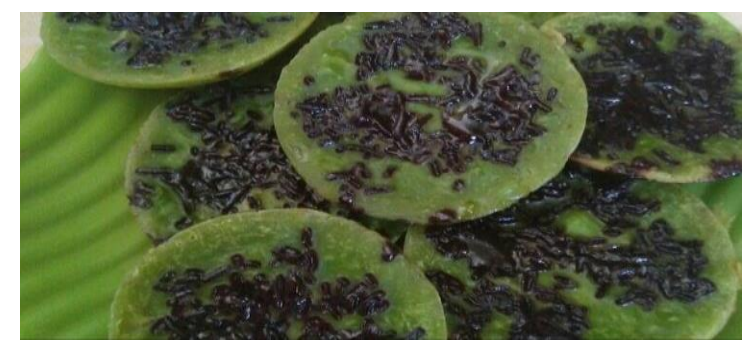

Gambar 4. Produk Serial (Serabi Milenial)

Analisis hasil pelaksanaan kegiatan P1000WB KKN New Normal 2020 antara lain:

\section{Penjualan}

Produk serial "Serabi Milenial" yang telah dibuat mendapatkan perhatian dan dukungan yang baik dari masyarakat. Hal ini dibuktikan dari hasil penjualan. Harga jual serial adalah 1.000/biji. Berikut hasil penjualan produk serial yang ditampilkan dengan grafik pada Gambar 1. Produksi dan penjualan dilakukan pada minggu kedua kegiatan KKN New Normal 2020. Jumlah produk yang terjual pada minggu kedua sebanyak 390 biji, pada minggu ketiga sebanyak 380 biji, minggu ke empat sebanyak 250 bij dan pada minggu ke lima sebanyak 220 biji. Pendapatan yang diperoleh dari penjualan serial pada minggu kedua yaitu Rp. 390.0000, minggu ketiga Rp. 380.000, minggu ke empat Rp. 250.000 dan minggu ke lima Rp. 220.000. Sedangkan keuntungan yang diperoleh dari penjualan serial pada minggu kedua yaitu Rp. 195.000, minggu ketiga Rp. 180.000, minggu keempat Rp. 125.000 dan minggu kelima Rp. 110.000. sehingga total jumlah produk yang terjual sebanyak 1.240 biji dengan total pendapatan Rp. 1.240.000. Dan total keuntungan sebesar $\mathrm{Rp}$. 620.000 .

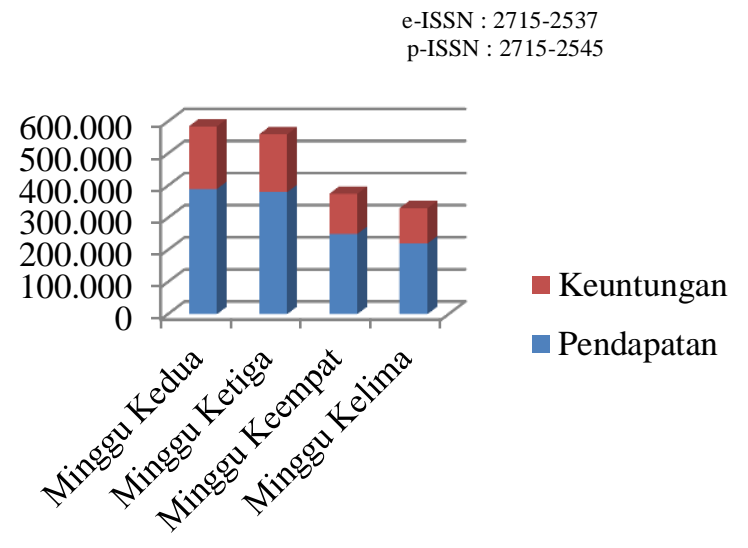

Gambar 5. Grafik Hasil Penjualan Produk Serial

\section{Analisis Usaha}

Analisis usaha dalam penjualan serial menggunakan perhitungan BEP, Cashflow selama enam belas hari dan ROI.

a. BEP (Break Event Point)

Harga jual satu biji kue serabi yaitu Rp. 1.000 dan harga variable satu biji kue serabi yaitu Rp. 500. Sehingga perhitungan BEP menjadi seperti berikut.

BEP kue serabi $=$ Total Biaya Tetap $/($ Harga jual - Biaya variabel)

$$
=\text { Rp. } 186.000 /(\text { Rp. } 1.000-
$$

Rp. 500)

$$
=372 \text { biji. }
$$

b. B/C Ratio

$B / C$ Ratio = Hasil penjualan (dalam

enam belas hari)/total biaya operasional

$$
\begin{aligned}
& =1 \cdot 240 \cdot 000 / \text { Rp. } 186 \cdot 000 \\
& =6,6
\end{aligned}
$$

Karena B/C ratio > 1 maka usaha ini layak dikembangkan.

c. ROI (Return On Investment)

ROI = Keuntungan (dalam enam belas hari)/total biaya operasional x 100\%

$$
\begin{aligned}
& =620.000 / 186.000 \times 100 \% \\
& =33 \%
\end{aligned}
$$

Rasio uang yang diperoleh sebagai keuntungan lebih besar dari uang yang dipakai untuk kegiatan operasional.

\section{Ketercapaian Target Luaran}

Target luaran yang telah dicapai dalam program KKN New Normal 2020 pada P1000WB ditampilkan dalam tabel berikut. 
Adawiah et al, Jurnal Pengabdian Masyarakat Sains Indonesia 2021, 3 (1): 235-239. DOI: https://doi.org/10.29303/jpmsi.v3i1.92

Tabel 1. Ketercapaian Target Luaran

\begin{tabular}{|c|c|c|c|}
\hline \multirow[t]{2}{*}{ No } & \multirow[t]{2}{*}{ Target } & \multicolumn{2}{|c|}{ Ketercapaian Target } \\
\hline & & Terlaksana & $\begin{array}{l}\text { Belum } \\
\text { Terlaksana }\end{array}$ \\
\hline 1. & $\begin{array}{l}\text { Survei alat dan } \\
\text { bahan produksi } \\
\text { dan sosialisasi } \\
\text { dengan } \\
\text { masyarakat }\end{array}$ & $100 \%$ & - \\
\hline 2. & $\begin{array}{l}\text { Pemenuhan } \\
\text { Alat dan Bahan }\end{array}$ & $100 \%$ & - \\
\hline 3. & $\begin{array}{l}\text { Pelaksanaan } \\
\text { Produksi }\end{array}$ & $100 \%$ & - \\
\hline 4. & Pemasaran & $100 \%$ & - \\
\hline 5. & Evaluasi & $100 \%$ & - \\
\hline 6. & $\begin{array}{l}\text { Laporan Akhir, } \\
\text { Pembuatan } \\
\text { Video, Leaflet } \\
\text { dan Artikel } \\
\text { Ilmiah }\end{array}$ & $100 \%$ & - \\
\hline & et Ketercapaian & $100 \%$ & - \\
\hline
\end{tabular}

Selama program ini berjalan, ibu-ibu $\mathrm{PKH}$ antusias untuk ikut serta dan berpartisipasi. Peluang pasar juga sangat menjanjikan untuk meningkatkan pendapatan mitra. Hal tersebut tampak pada kegiatan pelatihan, banyak orderan pemesanan kue serial yang berdatangan. Hanya saja waktu kegiatan pelatihan hanya berjalan dua hari karena terkendala oleh kegiatan ibu-ibu PKH yang pergi bekerja ke sawah. Dan ibu-ibu PKH masih belum percaya diri untuk meneruskan usaha serial sehingga perlu dibekali dengan wawasan dan skill yang berkaitan dengan hal tersebut.

\section{Kesimpulan}

Berdasarkan dari hasil pelaksanaan program, dapat disimpulkan beberapa hal berikut antara lain:

1. Usaha serabi milenial memang dapat dikembangkan dalam jangka panjang.

2. Keberlanjutan usaha serial ini akan diteruskan oleh masyarakat (ibu-ibu PKH).

3. Hasil analisis ekonomi usaha serial layak dikembangkan.

4. Metode pelaksanaan usaha serial dimulai dari tahap persiapan, tahap produksi, tahap promosi dan tahap evaluasi serta tahap pembuatan luaran program.
e-ISSN : 2715-2537

p-ISSN : 2715-2545

5. Strategi pemasaran dari usaha serial dilakukan dengan metode 4P (Price (harga), Place (tempat produksi dan pemasaran), Product (Produk) dan Promotion (Promosi).

\section{Saran}

Perlu adanya koordinasi dengan perangkat desa dan masyarakat setempat untuk melanjutkan usaha serial ini agar kegiatan pelatihan selanjutnya lebih sistematis dan terarah.

\section{Ucapan Terima Kasih}

Ucapan terima kasih kepada semua Dosen Pendamping Lapangan yang telah bersedia membimbing selama proses KKN New Normal 2020, Kepala Desa dan Staff Desa Borok Toyang yang telah membantu pelaksanaan KKN New Normal 2020 dan teman-teman KKN yang telah bekerjasama dan koperatif dalam menyelesaikan program ini.

\section{Daftar Pustaka}

Khoirunnisa, U. 2013. Pertumbuhan Industri Makanan akan Tetap Naik, http://sp.beritasatu.com/ekonomidanbis nis/pertumbuhan-industri-makananakantetap-naik/32680. diakses pada tanggal 30 Januari 2015 Pukul 18.45 WIB (GMT +7).

Suteja, I.W. dan Wahyuningsih, S. 2019. Strategi Pengembangan Potensi Kuliner Lokal dalam Menunjang Kegiatan Pariwisata di Kawasan Ekonomi Khusus Mandalika Kabupaten Lombok Tengah. Media Bina Ilmiah, 14,(2),: $2035-2042$.

Takaredase, J.T., Kaawoan, J.E. dan Singkoh, F. 2019. Program Keluarga Harapan Dalam Pengentasan Kemiskinan di Kampung Manumpitaeng. Jurnal Jurusan Ilmu Pemerintahan, 3,(3), 1-11. 